chip are severed together by a transverse cut. (See Fig. 2).

$\mathrm{R}$ em oval of the wedge shape chip from the spine of tibia stump, also removes an old objection, viz., the danger of the sharp bone cutting through the thin integument by ulceration. The flaps thus obtained make a fine, smooth and conical stump, without any crowding or stretching, and without redundance. They are of equal size. The surgeon is not puzzled with the task of trying to fit a fourinch flap to a six or eight-inch fellow. This plan presents many a dvantages over every ot her "method of cutting the flaps."

1. The avoidance of all after-trimıning.

2. Quicker and more certain union by first intention.

3. Drainage is complete, and pockets of ichor and pus avoided.

4. The stump presents no puckering or pouting corners.

The operation proved so suporior and satisfactory in the above case that it was adopted by several surgeons in our division of the army thereafter, for all amputations of leg, thigh and arm.

In all cases the stump is traversed by the cicatrix. Dr. Smith, and others, object to this result on the ground that it is " not firm and resisting, and not adapted to take direct support." This is a groundless fear, and has been long a bug-bear, and innocent obstacle to the work of the surgeon; for direct pressure on the stump is never borne, and never allowed. All successful legmakers permit no floor for tho stump to touch ur rest on; but support the entire weight of the body by the sides of stump, the condyles of the knee, and the tuberosity of the ischium.

In a cavalry boy, at Kenesaw Mountain, Ga., in January, 1864, whose leg was amputated by the above method in the lower third of the femur, it became necessary to re-open the stump to secure a bleeding artery, twenty-four hours after the operation. It was gratifying to witness how promptly the flaps had become glued together in initiatory union, requiring conaiderable force to separate them.

At the close of the war, while our division was encamped at Alexandria, near Washington, in May, 1865, Dr. Smith, while visiting the several divisions of the army, called on us; and on learning the particulars of our operation, expressed interest in it, and gratification at the result. He remarked that it was new to him, and inquired about its origin. Fergusson speaks of an operation (Lancet, July, 1865), as the "compromise," and thinks it appro. priate for the thigh and arm. But he transfixes the integument and cuts the deeper parts by the circular sweep. He therefore does not describe or follow our plan, which we believe suited to nearly all amputations; and when below the knee, it is infinitely superior to all others.

\section{COUP DE SOLEIL FOLLOWED BY PARALYSIS.}

By A. W. Catuin, Brooklyn, L. I.

As the following case of sunstroke is conceived to be rather unique in its bistory, and interesting in its rapid response to treatment, I beg leave to ask a small space in your JourNaL for its communication.

On July 20th, the patient, a boy of only three years of age, was brought into the house overcome with the heat. He had been playing for some time with his companions, without any protection to his head and neck while under the direct rays of a scorching sun; and, when found, he was constantly complaining of his head, with great heat and redness of the surface; great heat in bead, and symptoms of brain congestion. The pationt was constantly inclined to sleep, and, when roused, acted strangely. Ho did not seem to recognize any one. Pulse high; constant demand for water, \&c. This uccurred on Wednesday, but no medical advice was called in until the following Sunday, when the mother became alarmed, having noticod, the evening previous, for the first time, the child's complete inability to raise or use its right arm.

July 24th. -The little patient was found very much in the condition described above, though not quite so drowsy as he had been. Very irritable, and afraid of all but his mother. Found the right arm com- 
pletely powerless, hanging limp and useless at the side. Pupil on that side largely dilated. Lower limb not involved. Walks perfectly well. Treatment-cold to the head, previously shaved; mustard to the nape of the neck; mustard pediluviø three times daily; potassii bromidium, three grs. every three hours. Nourishment, beef tea.

July 31st.-Child much improved as to head symptoms. Acts naturally. Eats with some appetite, and seems interested in the games of his brothers around him. Right arm as before, save a slight flexor power in fingers.

Aug. 1st.-Commenced the use of electricity to-day, using Jerome Kidder's improved apparatus, current B-D. Mother takes it at the same time, so that its strength can be better estimated. Moist sponge; positive pole was applied to the cervical region of the spine, along the line of the brachial plexus, to the arm, and fingers which the mother held, she having negative pole in her right hand.

Aug. 6th.-Muscular power increasing ; able to flex forearm on arm.

Aug. 8th.-Improvement still going on. Complication of worms called for special treatment, and ol. chenopodii resulted in the child passing a dozen or more, of the species ascaris lumbricoides.

Aug. 30th.-The applications have been continued through the past two weeks every second or third day. The record states that the child is now able to raise the whole ar'm from the shoulder, and, with the exception of a slight hesitancy and slowness of movement, it is entirely restored.

Sept. 8th.-Quite well, but pupil on that side still slightly dilated.

This case is interesting and instructive, reminding us of the fact that children, even of tender years, are liable to sunstroke, and should be guarded therefrom; that the brain congestion which follows may be so intense as to result in effusion and hence paralysis. (A ustin Flint, however, states that paralysis is neither a concomitant nor a sequel to insolation.) To what, then, are we to ascribe the loss of muscular power in this case? The child had received no fall or injury ; that point was carefully inquired into, and, previous to this exposure to the sun, was perfectly well.

Attention is also called to the prompt and complete recovery which followed the use of electricity. Wo have used this agent before (not in similar cases), with but partial sucoess.

\section{DEFECTS OF OCULAR REFRACTION, \&.}

(Continued from pago 266.)

Lecture II. Part II.-Relalive Accommo. dation. Action of Glasses when used to assist Vision.

There is a relation between the accommodation and the convergence. Suppose, as normally is the case, that, when the visual lines are parallel, being directed to a distant object, each oye is then accommodated for parallel rays. If the visual lines subsequently converge to a point at a less distance $a$, each eye must then be accommodated for the now distance and must accordingly add to itself an amount of re. fractive power, 1 divided by $a$, over and above what it had when the visual lines were parallel. Thus a certain action of the accommodation becomes associated with a certain convergence.

Donders has experimentally shown that for a given convergence the adjustment admits of a certain range, called the relative range, that is, the range relative to the particular convergence; the relative nearpoint being nearer, and the relative farpoint being farther than the point of intersection of the two lines of vision, at which we suppose the object. It also appears from Donders's diagrams that for different convergences there are respectively different far-points ; as if the eye has a different refraction for different convergences. This last circumstance may be explained by supposing that the effort to converge carries with it a corresponding effort to accommodate, and that the latter cannot be relaxed entirely so long as the former continues. Acoording to Helmholtz, the curnea does not change its curvature in accommodation for near objects, and Knapp's observations tend to show that the lens admits of sufficient change to account for accommodation. Otherwise we might have hoped to explain the approach of the far-point for an increased convergence by supposing an elongation of the eye caused by pressure from without accompanying the conver: gence.

With regard to the measure of the relative accommodation, the amount by which the eye can accommodate nearer than the object for tho particular convergence is called the positive part; and the amount by which the accommodation can be relaxed beyond the object is called the negative part.

Donders distinguishes three meanings of the expression, range of accommodation: 